\title{
Theory of Technical Systems - Relationships to Engineering Sciences
}

\author{
W. Ernst Eder \\ Professor Emeritus. \\ eder-e@kos.net
}

\begin{abstract}
Products (process or tangible systems) are defined with reference to standard ISO9000:2005. Designing products with a substantial engineering content, technical systems (TS), means to fully describe them ready for manufacture - in detail and assembly drawings, parts lists, adjustment instructions, customer instructions, etc. Designing must take into account all recognized requirements, especially implied and stated requirements for the designingmanufacturing-distributing organization, the intended transformation process (TrfP), and all other phases of the TS-life cycle, including societal norms, economic considerations, etc. The theory of technical systems (TTS) and its associated engineering design science (EDS) provides a framework for design considerations about engineering products, including the technology, TS-life cycle, properties, and other aspects of artificial transformations and their operators. The triad 'theory - subject - method' suggests that a systematic engineering design method can be derived from TTS and EDS, to augment the usual intuitive design procedure, especially where the design problem is not routine. Engineering sciences are essential in this design process, (a) for analysis of existing systems and/or proposals for synthesis of designed systems, and (b) to assist as heuristics during design synthesis. Design synthesis is the more difficult operation, it requires iterative working. Several case examples have been published to demonstrate the application of the recommended systematic design method. Some of the relationships between engineering sciences and systematic design processes are explored to show their interdependence, and the need to provide a wider context in this area.
\end{abstract}

\section{Introduction}

A 'product' is defined by ISO 9000:2005 [1,2] as a 'result of any process', classified as:

a) hardware: tangible, material objects, with countable quantity; b) software: information, and intangible objects - insurance policies, laws, computer programs, etc., usually on hardware carriers;

c) service: intangible results of an activity (a process) performed at the interface between supplier and customer - providing electricity, water, fuel, transportation, garbage removal, policing, wholesale and retail, advertising, ambience, etc.; and

d) processed material: solid, liquid or gaseous (bulk) material that can be measured in units of volume, mass, energy, etc. - plastic pellets, fuel, grease, coolant liquid.

Energy is not uniquely classified by ISO (fuel appears in two sections). Electrical energy can be measured - implies 'processed material'. Some changes in hardware, software and/or processed material may be included in '(c) service', e.g. garbage removal treats garbage as hardware and processed material.

A classification better coordinated with the mathematical expressions of theories in the engineering sciences, and used in this paper is:

(A) living material - L - can only appear as operand being transformed,

(B) inanimate material $-\mathrm{M}$,

(C) energy - E, and

(D) information - I, including signals, commands, data, etc.

Where the products are manufactured or processed, both the product, its operational (usage) process (if applicable), and its manufacturing process needs to be established in advance of its existence - a process usually called 'designing'. If the designed product has a substantial engineering content, the product is either a transformation system, TrfS, or only a technical system, TS, and needs design engineering to satisfy the requirements. A classification of many sorts of products has been published [3 (Ch. I.7), 4 (Ch. 3)].

\section{Theory Of Technical Systems (TTS)}

A generalized theory to (non-mathematically) describe any artificial transformation and its causes (operators) and conditions has been under development since the 
1960's [3-12], and has been expanded to an engineering design science (EDS) $[3,4,11,12]-\mathrm{a}$ scientific explanation of the general phenomenon of design engineering (as a process) and its expected outcome, a full and implementable description of a proposed transformation system.

The concept of the system of Engineering Design Science (EDS) $[3,4,11,12]$ is based on the triad 'theory - subject - method' [13]: 'both theory and method emerge from the phenomenon of the subject'. A close relationship should exist between a subject (its nature as a concept or product), a basic theory (formal or informal, recorded or in a human mind), and a recommended method for voluntary application. A theory about a subject allows a method to be defined and heuristically applied, for using or for designing the subject.

A further consideration is that knowledge and information about design engineering can be 'mapped' onto two orthogonal axes, see figure $1[3,4,11,12]$. The north-south axis ranges from 'practice information' to 'theory knowledge'. The west-east axis ranges from 'information about existing transformation systems' to 'information about designing and design processes'. This points to the importance of (a) information about technical and other objects, existing and to be designed, and (b) information about design processes, including the mental activities and the methods that may be useful for designing.

Figure 1. Map of Engineering Design Science $[3,4,11,12]$

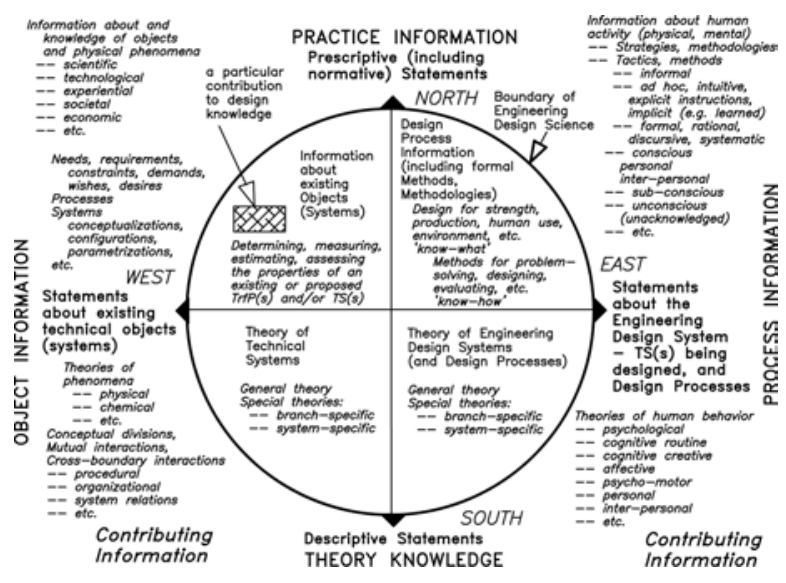

The basis of the theory of technical systems, TTS $[3,4,8,10]$, the south-west quadrant of figure 2 , is an axiomatically complete abstract model applicable for all (artificial, man-made) transformation systems, see figure 2 .
Figure 2. General Model of a Transformation System $[3,4]$

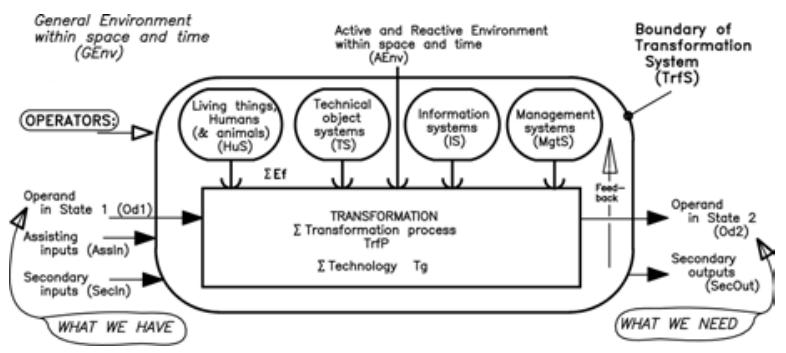

The model of the transformation system in figure 2 declares:

- An operand (materials, energy, information, and/or living things - M, E, I, L) in state Od1 is transformed into state Od2, using the active and reactive effects (in the form of materials, energy and/or information - M, E, I) exerted continuously, intermittently or instantaneously by the operators (human systems HuS, technical systems TS, active and reactive environment AEnv, information systems IS, and management systems MgtS, as output effects from their internal and cross-boundary processes, acting separately and/or jointly), by applying a suitable technology $\mathbf{T g}$ (which mediates the exchange of $\mathrm{M}, \mathrm{E}$, I between effects and operand), whereby assisting inputs are needed, and secondary inputs and outputs can occur for the operand and for the operators.

The operators can be active or reactive in their interaction with each other and in their technologyinteraction with the operand. For example, a bridge is almost purely reactive, a hand power tool is reactive to its human operator, but active towards the operand, an automotive automatic transmission is mainly active.

The operators can in most cases be regarded as full transformation systems in their own right. For instance, the management system performs its management process, driven by human managers, management technical systems, a management environment, a management information system, and an upper-level management system.

The general environment (regional, national and global) covers physical, chemical, societal, economic, cultural, political, ideological, geographic and all other influences indirectly acting on or reacting to the transformation system.

A generalized life cycle of technical systems, TS(s), is axiomatically complete, and consists of typically seven (classes of) transformation systems: LC1 - product planning, LC2 - designing the product, LC3 - technological and organizational preparation for subsequent life-cycle phases, especially manufacture and a supply chain, LC4 - manufacture and assembly, 
LC5 - distribution, LC6 - operation of the product, including tool changing, maintenance, repair, upgrading, LC7 - liquidation and disposal.

Classes of properties of existing transformation processes and technical systems are separated into observable (previously 'external'), mediating (previously 'internal'), and elemental design properties. TSobservable are the properties that anyone can see, assess and/or measure for the chosen boundaries of the TS. TS-mediating are the properties that are not observable, they are hidden by the chosen boundaries of the TS, and those related to the engineering experiential information (intrinsic properties, including mode of action) and engineering sciences (general design properties). TS-elemental design properties are those that are under the direct control of engineering designers during the design process, and include the TS-structures (function, organ and constructional, see figure 3), their elements and relationships, and for the elements the classes of arrangement, form, size, materials, anticipated manufacturing methods, deviations, surface quality, etc. Any one property can appear in one or more classes, and the classification can change according to the situation, e.g. a change of the assumed TSboundary and 'window' of attention [14].

Figure 3. Model of a Technical System - Structures $[3,4]$

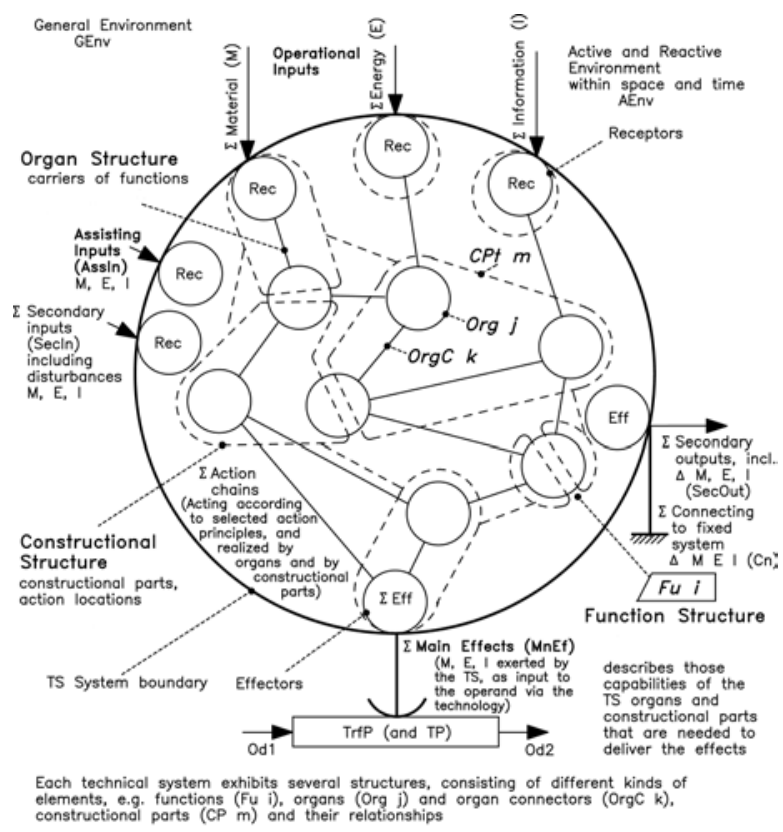

Conceptually, 'TS-internal' refers to the volume (or equivalent) occupied by TS itself. Properties include its crystal structure, depending on temperature changes, embrittlement, piezo-electric effects, state of static and dynamic stress, etc. A 'TS-enclosed space', not occupied by TS itself, is an 'interior' (usable) space, e.g. in a car for the operator and passengers, in a refrigerator for food and other items to be cooled, in a gas turbine for thermodynamic and gas-dynamic processes. These represent the transformation processes, TrfP, that must be considered 'TS-external' for the TS-boundary chosen at that time.

\section{Systematic Design Process}

The theory outlined in section 2 is the basis for the recommended systematic engineering design method, to be applied when needed.

Once the logic of the transformation system (TrfS), figure 2, and of the structures of TS, figure 3 , is understood, it is easily possible to derive a systematic approach to design engineering of transformation systems as products - usage processes, LC6, and technical systems, TS(s). Initially, a design specification (list of requirements) should be generated, including requirements for life cycle phases LC1 - LC3 (organizational requirements), for the transformation process (TrfP) and the technical system, TS(s) to be designed - recommendations for this have been published [4]. Attempting to satisfy such a list of requirements, a designer (or team) can establish (in approximately that order) a $\operatorname{TrfP}(\mathrm{s})$, the needed technologies, a suitable TS-internal and crossboundary function structure, a suitable TS-organ structure, and a suitable TS-constructional structure in preliminary layout, definitive/dimensional layout, and detail (first described in [5]). At each stage it is possible (advisable) to search for candidate alternative solutions, and to select the most promising for further processing, whilst keeping full records of the (temporarily) rejected solution proposals.

Any recommended systematic and methodical approach to design engineering must adapted (usually by the individual designer) to the personal style and experience, and parts or the whole used as needed for novel and re-design. Most published methods derived from other theories, from pragmatic practice, or intuitive approaches can be combined into this formal systematic method $[3,4]$.

Redesign is then easily accomplished by analyzing an existing TS-constructional structure (e.g. assembly drawing) to derive a TS-organ structure and a TSfunction structure, then altering the function structure to suit the new design specification, and proceeding with the systematic method towards a revised TSconstructional structure.

Normally, innovations are limited to a relatively small section of the engineering product, partly to 
limit the risks involved, partly to bring a 'new' product to market as quickly as possible. Sample case studies showing the application of this systematic approach, using models from the theory of technical systems $[3,4,8]$, are available $[3,4,9,15,16,17,18,19]$.

The apparent linearity of this procedure is only a broad approximation [20], parts of the $\operatorname{TrfP}(\mathrm{s})$ and/or TS(s) will inevitably be at different stages of concretization, and will force iterative and recursive working [21] - repeating a part of the design process with enhanced information to improve the solution proposals, and breaking the larger problem into smaller ones to solve and re-combine. In the process, the perceived or assumed TS-boundary is frequently redefined to restrict and focus the designer's 'window' of observation [14].

Superimposed on the systematic approach to design engineering is a frequently applied sub-process of problem solving (first defined in [6]). In its latest manifestation, this problem solving process appears as in figure 4. Noteworthy are the three auxiliary processes: Op-H3.5 'Prepare information', Op-H3.6 'Verify, check, reflect', and Op-H3.7 'Represent' these have not been specifically stated in any other model of problem solving.

Figure 4. Basic Operations - Problem Solving in the Design Process [3,4,22-28]

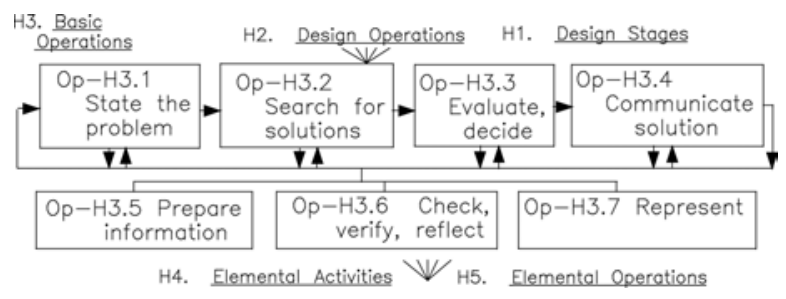

The main cycle, Op-H3.1-Op-H3.4, first published in [6], has recently been confirmed in cognitive psychology under the designation of 'creativity', with phases of 'analysis', 'generation', 'evaluation', and 'communication/implementation' the identity is obvious, with creativity residing mainly in Op-H3.2 and 'generation'.

\section{Engineering Sciences}

For design engineering, a knowledge of the individual relevant engineering sciences is absolutely necessary, but not sufficient. Designing also needs information that is not capable of description in scientific terms, stemming from technological experience (e.g. of manufacturing), human, societal, economic, and many other aspects. Much of this information is not available in mathematical form, but verbal, numerical and/or graphical representation is often available for interpretation. All the requirements given by a customer (or his/her representative) and demanded by the supplier and general society should be satisfied by the resulting products.

The engineering sciences formulate (usually mathematical) theories of behaviour of aspects of existing processes, TrfP, and tangible systems, TS, based on simplifying assumptions about the situation, usually looking at a single form of physical phenomenon in isolation. They are therefore essential (a) for analysis of existing systems, and of proposed solutions to design problems to determine its properties, and (b) for heuristic 'what-if' explorations and simulations - part of design synthesis [29,30]. Design synthesis is the more difficult operation, it requires iterative and recursive working.

Quasi-separate subjects covered include thermodynamics, statics and dynamics of mechanical system, strength and properties of materials, fluid statics and dynamics, electro-magnetic phenomena, digital and analog electronics, mathematics, and many others.

The engineering sciences are interdependent, yet any attempt to combine two or more individual engineering sciences would usually fail, the mathematical expressions would be far too complicated. Yet for both analytical and heuristicsynthesizing applications, a conceptual context and connectivity among these sciences must be established, especially in the mind of the user [31]. In addition, their use as heuristic tools towards designing must be developed and practiced.

\section{Relationships between TTS and Engineering Sciences}

The TrfS (and/or its operator TS) to be designed should (eventually) fulfill its required task, i.e. provide its performance as expected during usage. This means that the transformation process, TrfP, should become operational, the technologies, $\mathrm{Tg}$, should operate as expected, and the operators should behave as expected. Each of these can be analyzed by using the appropriate engineering (or other) sciences after (and/or during) designing, and these sciences can be used heuristically to assist in synthesizing the systems.

For the only operator that is subject to deliberate designing, the TS(s), its internal and cross-boundary constituents and their structures should be established in the design process as outlined in section 3. A TSfunction structure (with possible alternatives in arrangement and/or formulation) describes and establishes the required TS-internal and crossboundary behaviour, some of which can be analyzed 
and/or simulated from that function structure - maybe only in verbal and/or graphical terms.

With the help of a morphological matrix, a TSorgan structure (with alternatives) can be established, which provides a possible arrangement of the TSinternal 'mechanism' - usually without sizes such as wall thickness and distances between organs. By adding a (3D) overall geometry, a topology, analysis by engineering science techniques such as statics, freebody diagrams, kinematics, etc. becomes available.

Derived from the organ structure, a TSconstructional structure (with alternatives) in the form of a preliminary layout allows first heuristic use of strength of materials, electro-magnetic loading, etc. to establish estimates of required sizes from the appropriate engineering sciences. The TS-constructional structure can then be progressively refined, to a definitive (dimensional, true-to-size) layout, and detail and assembly drawings (or their computer-resident equivalents), with improved estimates of required sizes. CAD application is really only feasible from a dimensional layout into detail, although some CAD application programs can cope with changes in geometric proportions. Designing is complete if the future TS(s) is fully described in manufacturable form.

By (creatively) generating alternatives at every such level of abstraction, a sufficiently wide range of the solution space can be covered. In order to avoid combinatorial complexity, at each level of abstraction a choice should be made to select only the most promising alternative(s) - but this must be made reversible by good record-keeping, in case a selected alternative (at any level) becomes less promising. This procedure results in conceptual, verbal, graphical and/or mathematical optimization - the resulting proposed TS(s) will then likely be optimal, i.e. not a single optimum, it cannot exist to satisfy all potential customers/users, but close enough to satisfy most.

\section{Closure}

The insights about theory of technical systems, design processes, and engineering sciences presented in this paper give a reasonable argument for revising engineering curricula in all programs. It is necessary to provide a conceptual framework to connect the essential engineering sciences with each other, and with the needs of systematic design engineering. For this purpose, education in systematic and methodical design engineering is essential, and differentiates engineering graduates from science graduates. In this way, competent graduates who can take their place in industry with a minimum of further training can be educated.

\section{References}

[1] - ISO 9000:2005 Quality Management Systems Fundamentals and Vocabulary, Geneva: ISO, 2005 http://www.iso.ch.

[2] - ISO 9000:2005 Quality Management Systems Requirements, Geneva: ISO, 2005

[3] Eder, W.E. and Hosnedl, S (2008) Design Engineering: A Manual for Enhanced Creativity, Boca Raton: CRC-Press

[4] Eder, W.E. and Hosnedl, S (2010) Introduction to Design Engineering: Systematic Creativity and Management, Leiden, NL: CRC Press/Balkema

[5] Hubka, V. (1974) Theorie der Maschinensysteme, Berlin: Springer-Verlag

[6] Hubka, V. (1976) Theorie der Konstruktionsprozesse (Theory of Design Processes), Berlin: SpringerVerlag

[7] Hubka, V. (1978) Konstruktionsunterricht an Technischen Hochschulen (Design Education in Universities), Konstanz: Leuchtturm Verlag

[8] Hubka, V. and Eder, W.E. (1988) Theory of Technical Systems: A Total Concept Theory for Engineering Design, New York: Springer-Verlag

[9] Hubka, V., Andreasen, M.M. and Eder, W.E. (1988) Practical Studies in Systematic Design, London: Butterworths

[10] Hubka, V. and W.E. Eder (1992) Engineering Design, Zürich: Heurista

[11] Hubka, V. and Eder, W.E. (1992) Einführung in die Konstruktionswissenschaft (Introduction to Design Science), Berlin, Springer-Verlag

[12] Hubka, V., \& Eder, W.E. (1996) Design Science: Introduction to the Needs, Scope and Organization of Engineering Design Knowledge, London: Springer-

Verlag, http://deseng.ryerson.ca/DesignScience/ completely revised edition of [11])

[13] Klaus, G. (1965) Kybernetik in philosophischer Sicht (Cybernetics in Philosophical View) 4th edn., Berlin: Dietz Verlag, 1965 
[14] Nevala, K. (2005) Content-based Design Engineering Thinking, Academic Dissertation, University of Jyväskalä, Finland, Jyväskalä: University Printing House, http://cc.oulu.fi/ nevala

[15] Eder, W.E., 'Case Study in Design Enginee-ring' in Proc. CDEN 06 Toronto, 24-26 July 2006, on CDROM p. 332-338

[16] Eder, W.E. and Heffernan, P.J., 'A Case Study in Systematic and Methodical Design Engineering', in Proc. CDEN/C ${ }^{2} C^{2}$ Conference 2009, 27-29 July 2009, McMaster University, Hamilton, ON

[17] Eder, W.E., 'Case Study in Systematic Design Engineering - Smoke Gas Dust Precipitation', paper ASME DETC2009-86069 in Proceedings of the $6^{\text {th }}$ Symposium on International Design and Design Education, DEC 6, August 30 - September 2, 2009, San Diego, California, USA

[18] Eder, W.E., 'Case Study in Systematic Design Engineering - Trapeze Demonstration Rig', paper ASME DETC2010-28065 in Proc. $7^{\text {th }}$ Symposium on International Design and Design Education, DEC 7, 15-18 August 2010, Montreal, Quebec, Canada

[19] Eder, W.E., 'Case Study in Systematic Design Engineering - Automotive Oil Pump Redesign', paper ASME DETC2010-28073 in Proc. $7^{\text {th }}$ Symposium on International Design and Design Education, DEC 7, 15-18 August 2010, Montreal, Quebec, Canada

[20] Müller, J., Arbeitsmethoden der Technikwissenschaften - Systematik, Heuristik, Kreativität (Working Methods of Engineering Sciences, systematics, heuristics, creativity), Berlin: Springer-Verlag, 1990

[21] Eder, W.E., 'Requirements to Properties - Iterative Problem Solving', in Proc. Canadian Engineering Education Association 2010 Inaugural Conference, 79 June 2010, Queen's University, Kingston, ON

[22] Gregory, S.A. (1966) 'Design Science', in Gregory, S.A. (ed.), The Design Method, London: Butterworths, p.323-330, 1966
[23] Koen, B.V. (2003) Discussion of The Method: Conducting the Engineer's Approach to Problem Solving, New York: Oxford Univ. Press

[24] Schön, D.A. (1983) The Reflective Practitioner: How Professionals Think in Action, Basic Books, New York

[25] Schön, D.A. (1987) Educating the Reflective Practitioner: Towards a New Design for Teaching and Learning in the Professions, San Francisco: JosseyBass, 1987

[26] Wales, C.E., Nardi, A.H. and Stager, R.A. (1986a) Professional Decision-Making, Morgantown: Center for Guided Design (West Virginia Univ.)

[27] Wales, C., Nardi, A. and Stager, R. (1986b) Thinking Skills: Making a Choice, Morgantown, WV: Center for Guided Design (West Virginia Univ.)

[28] Wallas, G. (1926) The Art of Thought, London: Cape (reprint 1931) - p. 79-96 reprinted in Vernon, P.E. (ed.), Creativity, Harmondsworth: Penguin, 1970, p. 91-97

[29] Eder, W.E., 'Aspects of Analysis and Synthesis in Design Engineering' in Proc. Canadian Design Engineering Network Conference CDEN, 28-29 July 2008, Halifax, NS, on CD-ROM

[30] Eder, W.E. (2009) 'Analysis, Synthesis and Problem Solving in Design Engineering', paper 2-23, session W3 SIG-AEDS, in Proc. International Conference on Engineering Design, ICED 09, August $24-27$, Stanford University, Stanford, 2009, California, USA

[31] Litzinger, T.J., Lattuca, L.R., Hadgraft, R.G. and Newstetter, W.C. (2011) 'Engineering Education and Development of Expertise', Jnl Engineering Education (ASEE), Vol 100, No 1, p. 123-150, http://www.jee.org 